\title{
Tricuspid Regurgitation and Atrial Fibrillation Secondary to Contusio Cordis: An Atypical Presentation
}

\author{
Marcos Merula de Almeida*, Noemí Rocío Andrade Alban, Galo Juvenal Vinueza Aguay and Samira Nasr \\ Ghoraveb Kaissar \\ University of São Paulo, Brazil
}

Submission: June 26, 2018; Published: July 05, 2018

*Corresponding author: Marcos Merula de Almeida, University of São Paulo, São Paulo, Brazil, Tel: 5521983482971; Email: drmerula@gmail.com

\begin{abstract}
It is reported a case of a male patient, 42-year-old, with signs and symptoms of right heart failure and persistent atrial fibrillation (AF) after Contusio Cordis. The history revealed a chest trauma 11 years before, resulting in significant tricuspid regurgitation (TR) and biventricular dysfunction. It was performed elective surgery cardiac surgery of tricuspid valve with biological prosthesis, without complications in the immediate postoperative period. The patient obtained sharp improvement of symptoms, remaining in New York Heart Association (NYHA) functional class I.
\end{abstract}

Keywords: Tricuspid regurgitation; Thoracic trauma; Commotio cordis; Sudden cardiac death; Arrythmia

\section{Introduction}

The tricuspid regurgitation (TR) is most often associated with mitral valvular disease, named secondary tricuspid regurgitation. Other etiologies such as infective endocarditis, Ebstein's anomaly, carcinoid disease and blunt chest trauma are unusual [1]. The tricuspid valve lesions caused by blunt chest trauma are rare and often widely misdiagnosed. The term "contusio cordis" is represented by the cardiac myocyte damage, fibrotic or hemorrhagic, secondary to thoracic blunt trauma. Commotio cordis, meanwhile, involves electromechanical heart disorder. In most cases, leads to ventricular fibrillation, coinciding with a critical moment in the cardiac cycle- about $20 \mathrm{~ms}$ preceding the $\mathrm{T}$ wave [2]. Both presentations are usually fatal [3]. We report the case of a patient with a diagnosis of TR and atrial fibrillation (AF), secondary to contusio cordis, but with insidious and unusual late clinical evolution, diagnosed 11 years after the fact.

\section{Case Report}

The patient is a 42-year-old male, born in São Paulo, Brazil, complaining of palpitations and dyspnea on emergency department. New York Heart Association (NYHA) class III. History of thoracic trauma by car accident 11 years ago. Asymptomatic since then, starting 3 years ago with clinic of fatigue and dyspnea, with worsening over the past 8 months. On examination, he had irregular heart rhythms and holosystolic blowing in tricuspid focus, intensity $3+/ 6+$, with Rivero-Carvallo maneuver. Presence of hepatomegaly and edema of lower limbs. Chest teleradiography evidenced heart enlargement. Electrocardiogram showed irregular rhythm with the absence of $\mathrm{P}$ waves (atrial fibrillation) and right bundle branch block (Figure 1).

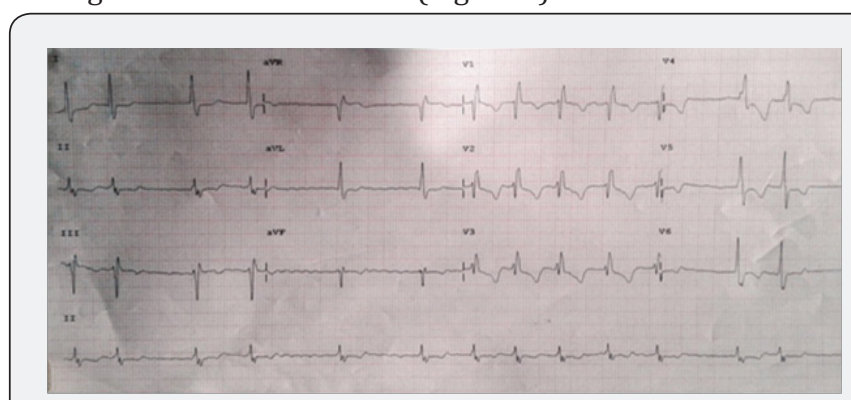

Figure 1: ECG shows atrial fibrillation+right bundle branch block.

The echocardiogram evidenced an increased left atrium (LA), with a diameter of $43 \mathrm{~mm}$, and ejection fraction (EF) of the left ventricle of $47 \%$. Confirmed important TR secondary to rupture of anterior cusp (Figure 2). Traction of the other cusps, secondary to right ventricular remodeling, generating important tricuspid reflux. Pulmonary artery systolic pressure of 38mmHg. Discrete systolic dysfunction of the left ventricle (LV). Moderate systolic dysfunction of the right ventricle (RV). Cardiac magnetic resonance 
imaging was also carried out to evaluate the RV. Image examination showed increased RV size, with moderate systolic dysfunction (EF 34\%). LV was enlarged with serious reduction of systolic function (EF 30\%). Absence of late enhancement areas suggesting fibrosis (Figure 3). With the diagnosis of TR secondary to contusio cordis, the patient underwent surgical treatment through median sternotomy. Intraoperatively confirmed the rupture of anterior tricuspid leaflet and dilation of the tricuspid ring. An attempt was made to tricuspid valve repair, with fixation of leaflet, but without success. Opted for tricuspid valve replacement with bioprosthesis (Figure 4). Patient evolved postoperatively without complications and NYHA functional class I.

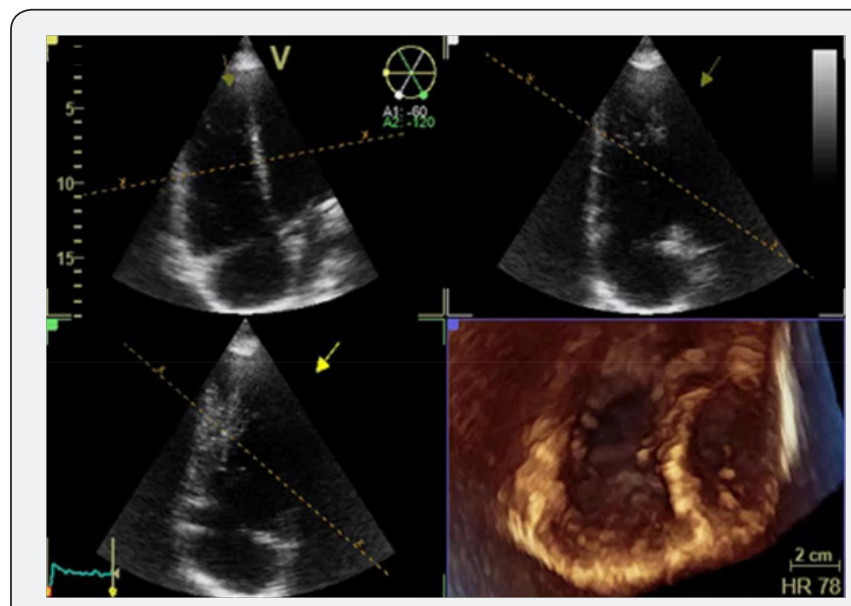

Figure 2: Transthoracic Echocardiogram showing rupture of the anterior cusp of tricuspid valve.

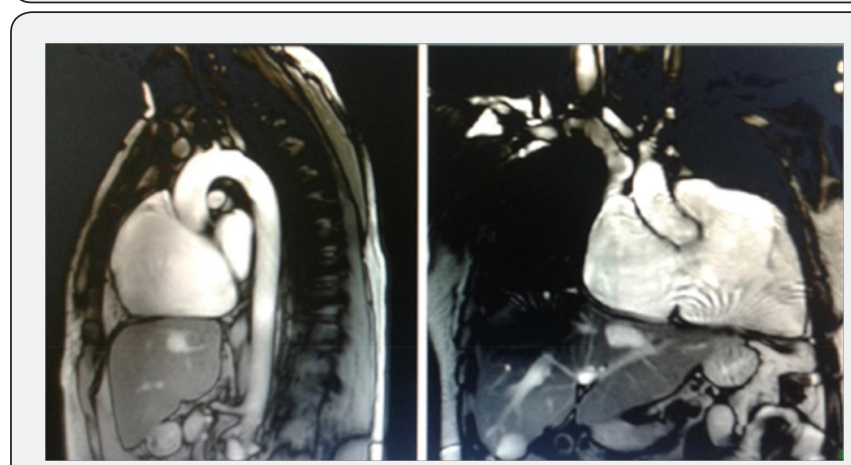

Figure 3 : Cardiac magnetic resonance imaging that shows the right ventricle $(R V)$ with increased dimensions.

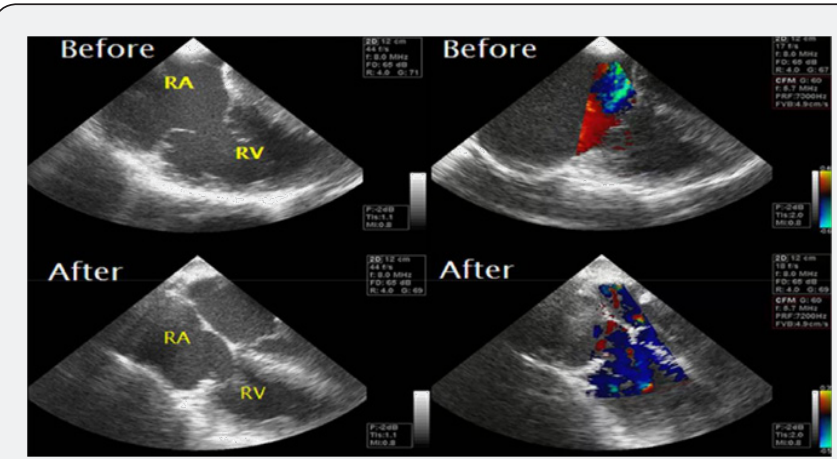

Figure 4: Tricuspid valve surgery result; that shows resolution tricuspid reflux. RA: Right Atrium; RV: Right Ventricle.

\section{Discussion}

The cardiac lesions resulting from chest trauma are varied, such as cardiac contusion, free wall rupture, septal rupture and valvular lesion [1]. Approximately 100 cases of traumatic cardiac lesions are described in the literature [4]. It can occur by a simple fall, impact on chest or after car accident. May be benign, with simple myocardial contusion, or lead to the destruction of cardiac structures, causing hemodynamic instability with imminent risk of death [5]. Commotio cordis involves high impact trauma, as in football, martial fights and car accidents. Occurs about $20 \mathrm{~ms}$ before the peak of the $\mathrm{T}$ wave, resulting in ventricular fibrillation [2]. The occurrence of AF in blunt chest trauma is rare [6]. The traumatic TR generates clinical manifestations correlated with the severity of the damaged structures, ranging from acute heart failure until subclinical manifestations [5]. In the majority of cases it is hemodynamically well-tolerated, resulting in underestimated incidence. The average time between trauma and valvular surgery is variable, with average time of approximately 17 years [7].

The mechanism of tricuspid valve lesion associated with contusio cordis is secondary to the severe impact during the enddiastole [8]. Due to the anatomical position, the right ventricle and the tricuspid valve present vulnerability to injury after frontal impacts. The high hydrostatic pressure on RV increases its vulnerability during diastole. The TR is caused by large strain both on papillary muscle and anterior cusp. In most cases, the progression is insidious and well tolerated [9]. The most commonly reported injury is the chordae rupture, followed by papillary muscle and leaflets ruptures [10]. After rupture of chordae, the valve function is usually preserved, especially on the cusp, coursing with a subacute clinical presentation or even late. The rupture of the papillary muscle generates immediate and severe hemodynamic instability, determining an acute presentation [11]. In the case that we report, the TR was diagnosed 11 years after a minor chest trauma, with a clinical course characterized by slow development of heart failure. The ideal time for surgery in traumatic TR is still controversial. The traditional indication of surgical approach is the symptomatic heart failure, and its early realization after the initial symptoms could prevent cardiac remodeling [12].

The surgical treatment for the TR includes the valve repair or its replacement. Valve repair are effective and, when possible, represents the gold standard [13-15]. Early diagnosis and surgical treatment can facilitate the valve repair technique and prevent the deterioration of the function of RV [16]. However, the possibility of valve repair represents the minority of cases [17], because of the presence of fibrosis or excessive secondary annular dilatation in most of cases. In the case reported, valve repair was attempted, but without success. The patient was submitted to tricuspid valve replacement with prosthesis.

\section{References}

1. Nelson M, Wells G (2007) The traumatic tricuspid valve regurgitation 
off case caused by blunt chest trauma. J Am Soc Echocardiogr 20(2): 198.e4-e5.

2. Maron BJ, Estes NA (2010) Commotio cordis. N Engl J Med 362(10): 917-927.

3. Alawi AA, Madias C, Supran S, Mark SL (2010) Marked variability in susceptibility to ventricular fibrillation in an experimental commotio cordis model. Circulation 122(24): 2499-2504.

4. Turkoz R, Gulcan O, Atalay H, Uguz E (2007) Surgical repair of tricuspid valve regurgitation caused by blunt thoracic trauma. J Trauma 63(1): E7-E9.

5. Krasna MJ, Flancbaum l (1992) Blunt cardiac trauma: clinical manifestations and management. Semin Thorac Cardiovasc Surg 4(3): 195-202.

6. Ghose RR (1998) Commotio cordis and atrial fibrillation. N Z Med J 111(1075): 394.

7. Van Son JA, Danielson GK, Schaff HV, Miller FA (1994) Traumatic tricuspid valve insufficiency: experience in thirteen patients. J Thorac Cardiovasc Surg 108(5): 893-898.

8. Banning AP, Durrani A, Pillai R (1997) Rupture of the atrial septum and tricuspid valve after blunt chest trauma. Ann Thorac Surg 64(1): 240-242.

9. Tütün U, Aksöyek A, Parlar AI, Cobanoğlu A (2011) Post-traumatic tricuspid insufficiency: a case report. Ulus Travma Acil Cerrahi Derg 17(6): 563-566.
10. Werne C, Sagraves SG (1989) Mitral and tricuspid Costa c. valve rupture from blunt trauma sustained during a motor vehicle collision. The Journal of Trauma 29(1): 113-155.

11. Perlroth MG, Hazan E, Lecompte Y, Gougne G (1986) Chronic tricuspid regurgitation and bifascicular block due to blunt chest trauma. Am J Med Sci 291(2): 119-125.

12. Maisano F, Lorusso R, Sandrelli L, Torracca L, Coletti G, et al. (1996) Valve repair for traumatic tricuspid regurgitation. Eur J Cardiothorac Surg 10(10): 867-873.

13. Katz NM, Pallas RS (1986) Traumatic rupture of the tricuspid valve: repair by chordal replacements and annuloplasty. J Thorac Cardiovasc Surg 91(2): 310-314.

14. Noera G, Sanguinetti M, Pensa P, Biagi B, Cremonesi A, et al. (1991) Tricuspid valve incompetence caused by nonpenetrating thoracic trauma. Ann Thorac Surg 51(2): 320-322.

15. Bolton JW (1996) Traumatic tricuspid valve injury: leaflet resuspension repair. Ann Thorac Surg 61(2): 721-722.

16. Richard P, Vayre F, Sabouret P, Gandjbakhch I, Ollivier JP (1997) Outcome of traumatic tricuspid insufficiency, treated surgically. Apropos of 9 cases. Arch Mal Coeur Vaiss 90(4): 451-456.

17. Schuster I, Graf S, Klaar U, Seitelberger R, Mundigler G, et al. (2008) Heterogeneity of traumatic injury of the tricuspid valve: A report of four cases. Wien Klin Wochenschr 120(15): 499-503.

\section{Your next submission with Juniper Publishers} will reach you the below assets

- Quality Editorial service

- Swift Peer Review

- Reprints availability

- E-prints Service

- Manuscript Podcast for convenient understanding

- Global attainment for your research

- Manuscript accessibility in different formats

( Pdf, E-pub, Full Text, Audio)

- Unceasing customer service

Track the below URL for one-step submission https://juniperpublishers.com/online-submission.php 